\title{
Errando se aprende
}

\author{
Ana Rodríguez Allen ${ }^{1}$
}

Podemos, es cierto, saber muchas cosas. Si no podemos saberlo "todo", según la posición tradicional, se debe simplemente a que con el término "todo" no podemos hacer casi nada, ya que con cada nuevo descubrimiento aparece por lo menos un nuevo problema: La investigación de lo que acaba de ser conocido. A partir de aquí el número de los problemas a resolver se hace infinito y la designación "todo" se convierte en absurda.

Ludwik Fleck

Hace varios años me compré un libro titulado Problemas y experimentos científicos del pedagogo Yákov Perelmán, autor -que según el científico Tsiolkovski- era conocido por sus "obras populares, ingeniosas y completamente científicas sobre física, astronomía y matemáticas, escritas además con un estilo maravilloso y fácil de asimilar para los lectores".

$\mathrm{Me}$ entretuve resolviendo los enigmas que allí se planteaban y pensé en las posibilidades pedagógicas que

1. Filosofa costarticense. Universidad Nacional de Costa Rica. 
tendrían estos acertijos en el aula. La oportunidad para desarrollar este potencial se me presentó cuando me solicitaron algunas charlas acerca del constructivismo-crítico, que correlaciona las ideas y explicaciones sobre los fenómenos con las diferentes concepciones de mundo. Es un elemento fundamental la crítica -palabra utilizada en griego antiguo para designar la acción de tamizar la arena para encontrar el oro- ya que el conocimiento se construye a través del diálogo y el contraste entre las diferentes opiniones. El aula se convierte en un espacio social de participación activa donde se exponen y confrontan ideas, se asigna valor a la diferencia y se promueve su respeto construyendo nuevos conocimientos a partir de nociones, especulaciones y fantasías sin temor a equivocarse y ser censurado. Resulta imprescindible que el problema o el tema planteado impacte en la subjetividad de los participantes.

Siguiendo la tesis popperiana de que la ciencia empieza con problemas y utilizando los ejemplos recogidos por Perelmán para discutir sobre ciencia y pedagogía he tenido la posibilidad de comprobar las premisas del constructivismo crítico a través de mi propia práctica en el aula a lo largo de los años. Esta es la reflexión planteada en este artículo que versa sobre la variedad de reacciones que un mismo ejemplo provoca en públicos diferenciados.

La primera ocasión en la que utilicé los ejemplos de Perelmán fue con el equipo de Medicina Preventiva de la Caja Costarricense del Seguro Social, tomé uno de los ejercicios planteados en el libro que me parecía podía ser suficientemente provocador y les narré uno de sus cuentos.

Se trataba de dos hermanos. El hermano mayor invitaba al menor a hacer experimentos con una máquina que llevaba en la billetera. La máquina era una hoja grande de periódico que -decía el hermano mayor- es un aparato físico: 
"(...) ahora verás como este mismo periódico se hace pesadísimo. ¡Dame aquella regla de dibujo! (...) Mi hermano puso la regla sobre la mesa, de modo que una parte de ella sobresalía del borde. (...) Extendió el periódico en la mesa, le alisó cuidadosamente los piegues y tapó con él la regla.

-Coge un palo y da un golpe fuerte sobre la parte de la regla que sobresale. ¡Dale con todas tus fuerzas!

- Le voy a dar un golpe, que la regla romperá el periódico y saltará hasta el techo-dije yo, y levanté el palo.

-No escatimes fuerzas"2.

Llevé a la charla el papel periódico, una regleta de madera y un martillo e invité a los participantes a pronosticar el resultado antes de llevarlo a la práctica. Las conjeturas fueron muchas, pero la mayoría supuso que el periódico se rompería o volaría al darle a la regleta con el martillo. Debo decir que la discusión duró alrededor de una hora, lo cual me mostró cómo las personas construyen e interpretan sus hipótesis y cómo también tratan de imponerlas a los demás sin escuchar razones, siguiendo criterios de autoridad en la mayoría de los casos. El público estaba conformado por profesionales de la salud: médicos, enfermeras, psicólogas y trabajadores śociales. Este último grupo planteó un número significativo de soluciones acerca de lo que iba a suceder con el papel cuando el martillo golpeara la regleta; mientras que el grupo de ciencias médicas sostuvo en todo momento como única solución que el papel se rompería y que no hacía falta gastar más tiempo en especulaciones. No estaban dispuestos a escuchar otras posturas, actitud muy relacionada con los criterios de infalibilidad sobre los que se sustenta la práctica profesional médica. Esta

2. PERELMAN, Ya.i. Problemas y experimentos científicos. Moscú: Editorial MIR, 1975, p. 98 
discusión permitió introducir el tema de los paradigmas en las ciencias y los enfrentamientos entre los diferentes grupos y las concepciones en que se basan, como por ejemplo el caso de la concepción de salud de las curanderas y las brujas y la concepción científica médica patriarcal.

En otra ocasión volví a utilizar el mismo problema con profesorado de secundaria en el área de ciencias. Esta vez trabajé junto con un colega que levantó una bitácora ${ }^{3}$, de las las hipótesis, especulaciones y estilos de trabajo para resolver el problema que se produjeron durante la sesión. Después de una ardua discusión el grupo de profesoras dijo que no darían una respuesta hasta que hiciéramos el experimento. Ellas parecían suponer que el papel volaría pero se abstuvieron de asegurarlo mientras éste se llevara a cabo. El grupo quedó estupefacto cuando se rompió la regleta y el papel no voló, incrédulas volvieron a repetir el experimento y la regleta se rompió nuevamente. El colega había anotado con detalle el comportamiento y las ideas que iban expresando las participantes e introdujo un interesante elemento de análisis de género en el encuadre didáctico que armó un polvorín en la clase: mientras que los profesores desarrollaron una actitud pasiva y se limitaron a esperar los resultados hablando de otros temas, las profesoras mantuvieron una actitud crítica al especular con los posibles resultados del fenómeno. Como más tarde él me reconocería había cometido "un error" dentro de la moral tradicional masculina y su comentario era una deslealtad de género al poner en evidencia un comportamiento típico en estos casos que, por usual, hemos asumido como natural y apenas percibimos.

Desarrollé este experimento con estudiantes universitarios de biología, en cursos de bioética y epistemología. Siguiendo la metodología que se utiliza en los ensayos

3. MEONO, Rodolfo. Anotaciones, 2000 
científicos: tanteo y error, quise saber si el fenómeno se repetía y me preguntaba si se plantearían los mismos problemas. Como en anteriores foros, los estudiantes concluyeron que la regleta no se rompería o que el papel volaría. Sin proporcionarles la respuesta correcta les solicité que investigarán cómo se resolvía este problema consultando, para ello, a sus profesores de química o de física. Aunque las respuestas que obtuvieron fueron variadas $y$, algunas erradas, compartían cierto grado de abstracción y un lenguaje críptico que los estudiantes no lograban comprender ni aplicar en la resolución del problema, la explicación de un colega de física para resolver él problema fue: Presión atmosférica $1 \times 10^{\wedge} 5.1 \mathrm{~cm}^{\wedge} 2=000,0001.1 \times 10^{\wedge} 5 \mathrm{~N} / \mathrm{m}^{\wedge} 2 \times 1 \times 10 \wedge$. $4 \mathrm{~m}^{\wedge} 2=10 \mathrm{~N}=1 \mathrm{~kg}$. Aunque la formula era simple: Presion $=F /$ A (fuerza/aire), resultaba ininteligible para los estudiantes, que no habían incorporado el lenguaje científico, a pesar de que ya habían llevado cursos de física y química.

Al igual que en el siglo XIX, en el que se consideraba mágico o milagroso, que una corriente eléctrica pudiera desviar a cierta distancia la aguja de una brújula, se suele calificar de sobrenatural aquello que no se comprende y parte del alumnado me preguntó cuál era el truco de magia que ocultaba el experimento. Y es que, si consideramos su raíz etimológica, la palabra magia del griego magikós significa encantar y, el mágos tiene entre sus muchas acepciones la de sacerdotisa, sabio, interpréte de los sueños y maestra. De aquí que algunas de las personas que ejercemos la docencia debamos usar algunos sortilegios para que nuestra materia sea comprendida.

Como contraste con la explicación física, expuse ante el alumnado la, mucho más didáctica, elaborada por Perelmán que dice así:

"-Esto es el quid del experimento. Sobre el periódico presiona el aire y... con no poca fuerza: cada centímetro 
cuadrado de la hoja de periódico es apretado por él con la fuerza de un kilogramo. Cuando se golpea el extremo de la regla que sobresale, ésta presiona con su otro extremo, desde abajo, sobre el papel y el periódico debe levantarse. Si esto se hace despacio, debajo del periódico, que empieza a levantarse, tiene tiempo de entrar aire desde fuera, el cual con su presión, equilibra la que sufre el periódico por arriba. Pero tu golpe fue tan rápido, que el aire no tuvo tiempo de penetrar debajo del periódico: el borde de la hoja de papel aún estaba en contacto con la mesa, cuando su parte central ya era empujada hacia arriba. Por esto tuviste que levantar no sólo el periódico, sino también el aire que presionaba sobre él. En resumidas cuentas: hubieras tenido que levantar con la regla un peso aproximado igual a tantos kilogramos como centímetros cuadrados tiene la parte del periódico a levantar. Si ésta fuera una parte del papel de sólo 16 centímetros cuadrados - un cuadrito de 4 centímetros de lados-, la presión del aire sobre él sería de 16 kilogramos. Pero la parte del papel que había que levantar era considerablemente mayor, por lo tanto, el peso a levantar era grande, quizá de medio ciento de kilogramos. La regla no aguantó este peso y se rompio" ${ }^{\prime 4}$.

La última vez que utilicé este experimento fue en un curso de ciencia y género para feministas. En esta ocasión la discusión giró en torno a la ciencia como una construcción social y sus implicaciones políticas. Las estudiantes se centraron en los valores que subyacen en la experimentación científica y que afectan primordialmente a las mujeres. Una de las categorías que vertebró la discusión fue la de invisibilidad. Se ilustró con numerosos ejemplos cómo el reconocimiento social de los descubrimientos científicos

4. PERELMAN, Ya.l. Problemas y experimentos cienúficos. Moscú: Editorial MIR, 1975, p.99 
invisibiliza el trabajo en equipo -atribuyendo el mérito a una sola persona no tanto por su aporte al experimento sino por la posición que ocupa en la institución científica-, y cuál es la distribución genérica de los puestos de poder en las instituciones.

Lo más interesante de estas experiencias pedagógicas ha sido observar cómo las personas utilizan múltiples recursos como la imaginación, la memoria, el intercambio de opiniones y hasta de pensamientos fósiles -en el sentido de Ludwik Fleck ${ }^{5}$-, para resolver una situación hipotética que les resulta interesante y significativa. Igualmente se ha mostrado cómo los diferentes grupos enfrentan el acertijo de manera distinta en dependencia de sus adscripción, intereses y creencias. Este proceso ha resultado enriquecedor no sólo por constatar los resultados de las presuposiciones y especulaciones de los otros, sino también las nuestras. Finalmente, la puesta en práctica de la pedagogía constructivista crítica desmitifica el conocimiento científico como un espacio vedado a los no iniciados y fortalece la capacidad personal de entender y explicar el mundo superando el miedo a equivocarse, al fin y al cabo, la ciencia se ha construido a partir de errores.

5. CF. FLECK, Ludwik. La genesis y el desarnollo de un hecho cienufico. Madrid: Alianza Editoriai, 1986. 